Annals of International Medical and Dental Research

E-ISSN: 2395-2822 | P-ISSN: 2395-2814

Vol-8, Issue-2 | March-April 2022

DOI: 10.53339/aimdr.2022.8.2.6

Page no- 25-33 | Section- Research Article (Optometry)

\title{
Anterior Segment Optical Coherence Tomography In Scleral Lens Fitting
}

\author{
Saima Ahsan Mazumder ${ }^{1}$, Nazmul Mazumder ${ }^{2 *}$
}

1B. Optom (AIIMS-New Delhi), M. Optom (NIMS-Jaipur)- Optometrist - Working at Dr. RPC, AIIMS- New Delhi, India.

Email ID: s.ahsan91@yahoo.com,

Orcid ID: 0000-0001-6491-0407

2B. Optom (AIIMS-New Delhi), M. Optom (SU-RJ), PGDEMA- Optometrist- Working at JJSV- Delhi, India.

Email ID: namaiims@gmail.com,

Orcid ID: 0000-0003-3073-3486

*Corresponding author

Received: 30 August 2021

Revised: 13 October 2021

Accepted: 27 October 2021

Published: 18 February 2022

\section{Abstract}

Background: AS-OCT is a noncontact imaging device that provides the detailed structure of the anterior part of the eyes. The Objectives In this review, the author will discuss the clinical applications of AS-OCT in the scleral contact lens fittings. Material \& Methods: Pre-Scleral lens fit and post fit ASOCT done on 30 patients to assess the normal fitting and compare it with the slit lamp evaluation. Results: ASOCT gives a Quantitative measurement of the fit. Conclusions: ASOCT comes out as a helpful tool for beginners particularly for a good assessment of a contact lens fit. The author also presents some interesting cases demonstrated via AS-OCT.

Keywords:- Scleral Lenses, Central and Peripheral clearances, edge assessment using ASOCT

\section{INTRODUCTION}

Scleral Lenses are all lenses that have their resting point in parts beyond the corneal

\section{Indications:[3]}

\begin{tabular}{|l|l|l|}
\hline & Primary Indications & Secondary Indications \\
\hline A) & $\begin{array}{l}\text { Vision Correction: } \\
\text { These lenses are highly beneficial for vision } \\
\text { restoration of irregular corneas which } \\
\text { includes conditions like }\end{array}$ & $\begin{array}{l}\text { Drug Delivery:[5] } \\
\text { Scleral lenses have also shown their indication } \\
\text { for the application of antibiotics. }\end{array}$ \\
- Keratoconus & \\
- Keratoglobus & $\begin{array}{l}\text { Pellucid marginal Degeneration. [4] } \\
\text { Post refractive surgeries such as Laser } \\
\text { assisted in situ Keratomileusis (LASIK) }\end{array}$ & \\
Keratoplasty (LASEK) & Post Photorefractive keratectomy (PRK),
\end{tabular}


Annals of International Medical and Dental Research

E-ISSN: 2395-2822 | P-ISSN: 2395-2814

Vol-8, Issue-2 | March-April 2022

DOI: $10.53339 /$ aimdr.2022.8.2.6

Page no- 25-33 | Section- Research Article (Optometry)

\begin{tabular}{|c|c|c|}
\hline & $\begin{array}{ll}\text { - } & \text { Post Radial Keratotomy (RK) } \\
\text { - } & \text { Trauma } \\
\text { - } & \text { Corneal Transplants. }\end{array}$ & \\
\hline B) & $\begin{array}{l}\text { Corneal Protection: } \\
\text { Retention of a fluid reservoir behind the } \\
\text { scleral lenses benefits a lot in the role of } \\
\text { protection of cornea. This may include } \\
\text { conditions such as } \\
\text { - Sjogren's Syndrome. } \\
\text { - Steven's Johnson Syndrome. } \\
\text { - Ocular Cicatrial Pemphigoid.[6] } \\
\text { - Neurotrophic Corneal Disease. } \\
\text { - Atopic Keratoconjunctivitis.[] } \\
\text { - Chemical burns. }\end{array}$ & $\begin{array}{l}\text { Cosmetic: } \\
\text { Scleral lenses can be used for cosmetic reasons } \\
\text { in Ptosis. } \\
\text { Hand painted Scleral lenses can be used in } \\
\text { Atrophic bulbi also tinted or coloured scleral } \\
\text { lenses are used in film industry for special } \\
\text { effects. } \\
\text { Moreover painted scleral lenses also reduce } \\
\text { glare in Aniridia and Albinism. }\end{array}$ \\
\hline
\end{tabular}

Scleral Lenses in corneal irregularities help to achieve improvements in vision and comfort. They vault over cornea and rest on the sclera, thus creating a new optical surface and preventing discomfort by minimising irritation to the cornea. The Saline solution reservoir between the lens and the cornea provides a fluid environment for cornea thus providing health and comfort.

Although, conventional lens fitting has improved with time, with highly aspheric and quadrant specific lens designs, $[9,10]$ but still it causes mechanical stress on the cornea as they rest on it and hence re not readily accepted by advanced keratoconic patients. For a good corneal clearance, reducing mechanical stress and for better optics, Scleral lenses, are a better option.

\section{MATERIAL AND METHODS}

30 patients were included in the study. These included patients with corneal hydrops, SJS, Chemical injury, RK, Keratoconus, and scar etc. Patients are assessed and fitted with scleral contact lenses.

Before the fitting, Slit Lamp evaluation is done and a baseline ASOCT is captured. Scleral Lens is fitted and then the slit lamp evaluation is done with fluorescein and ASOCT is done to quantitatively measure the central vault or clearance, Peripheral curve, and edge lift and the patient's comfort is evaluated. ASOCT used for this is Optovue.

\section{Anterior Segment Optical Coherence Tomography (ASOCT)}

ASOCT is a non-contact method for high resolution,[11] cross sectional and Three Dimensional imaging of cornea and anterior segment of the eye.

\section{Applications}

ASOCT has a numerous research and clinical applications such as:[12] 
Page no- 25-33 | Section- Research Article (Optometry)

- In Glaucoma for viewing the angle, and also to depict the patency of glaucoma implants in the anterior chamber (Open and closed angles).

- In Phakic IOLs, to see lens centration and quantitative measurement of its vault

- In measuring tear prism height

- In Post refractive surgeries such as LASIK/ SMILE - to measure the flap in Lasik and the lenticule in SMILE.

- Posterior Capsule Status prior cataract surgeries

- Corneal transplants -To measure donor and host thickness as well as the graft host junctions alignment.

- Pachymetry and epithelial mapping

- Ocular Surface disorders and diseases

- Evaluation of Speciality and custom design Contact Lenses.

\section{Ideal Scleral Lens Fit.[1]}

- Vaulting over the cornea and the limbus (Clearance or Sagittal Height)

- Proper Landing Zone (Haptic or Scleral zone.

- Adequate tear exchange under the lens.

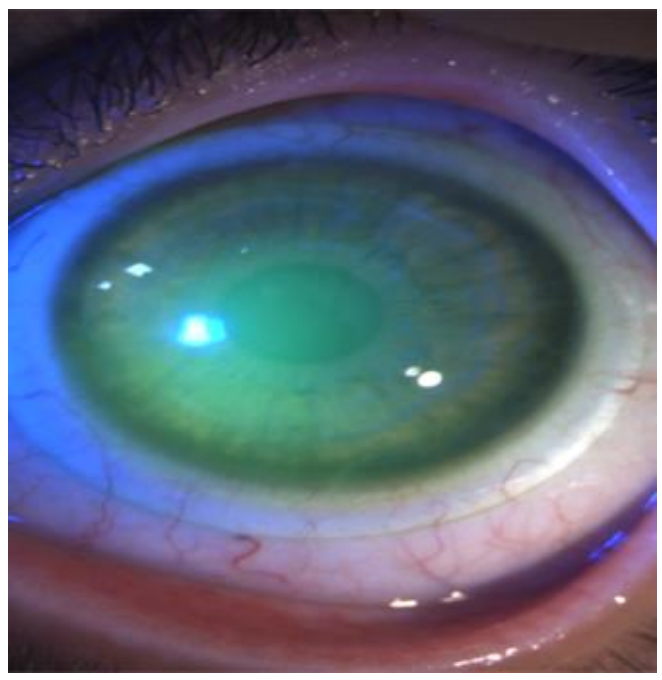

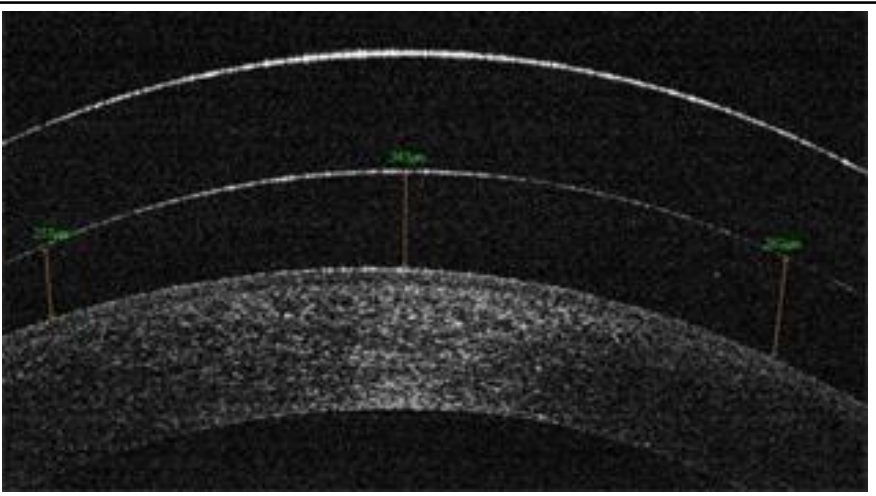

RESULTS AND DISCUSSION

\section{Fitting Scleral Contact Lenses-Whilst Evaluation with Asoct}

\section{Clearance:}

An optimal level clearance is that which provides a stable and comfortable lens fit with good vision, minimal post lens tear layer debris, and minimal physiological disturbance to the central and peripheral cornea. It can be understood by lens sag or Sagittal height.

The term sagittal height means the amount of space between the lens and the cornea or it actually refers to the entire contact lens from the center of the lens to the plane that the edges circumscribe. Larger diameter lenses have deeper sag and greater the clearance.

\section{a) Central Corneal Clearance:[14]}

A clearance of 200-300 microns is usually considered sufficient for a good fitting. Clearance, using slit lamp, can be judged by using known or estimated corneal thickness and comparing the slit width to the width of the space between the lens and cornea called as Tear Layer. Typically vault should range between $25-100 \%$ of corneal thickness. 
Annals of International Medical and Dental Research E-ISSN: 2395-2822 | P-ISSN: 2395-2814

Vol-8, Issue-2 | March-April 2022

DOI: 10.53339/aimdr.2022.8.2.6

Page no- 25-33 | Section- Research Article (Optometry)

The Human eye is capable of observing 20 microns or more of fluorescein layer thickness and anything less will appear black but this does not mean there is a touch.[15]

ASOCT in such cases is very useful as it can quantitatively give a finite location of touch and also the amount of minimum clearance in an area.

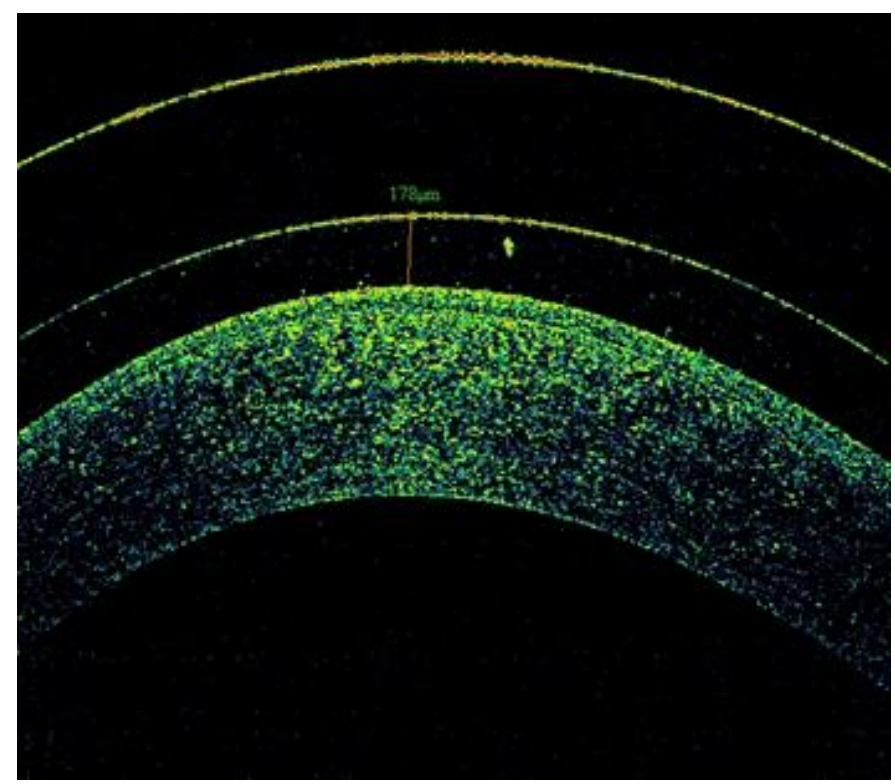

Figure: An Ideal Fit

Here is an image of a patient of post operative Radial keratotomy with a touch at a location slightly away from the centre as seen in an ASOCT followed by its clinical image below. [16]
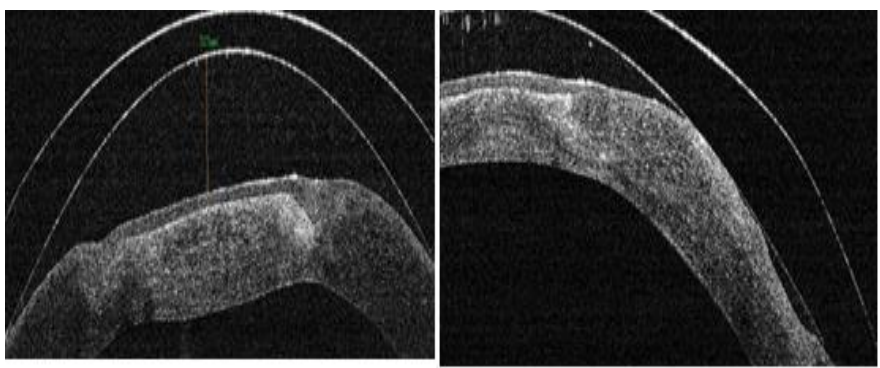

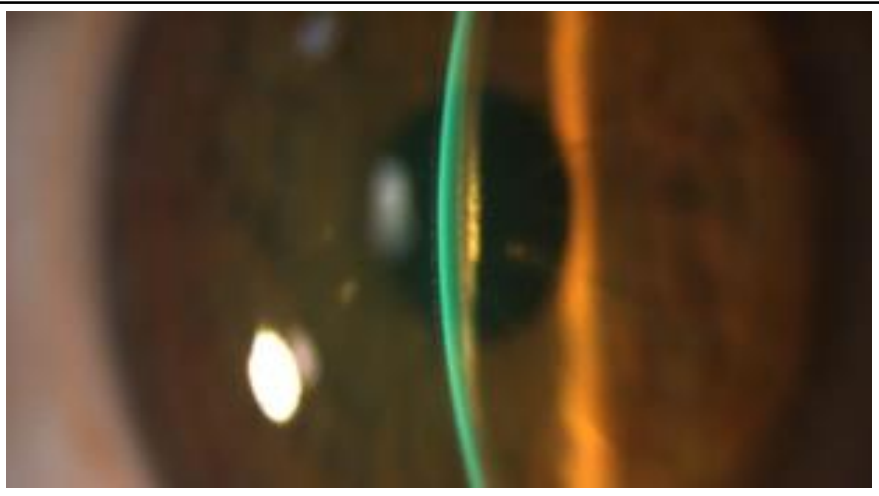

Below is an another image of a patient with an advanced Keratoconus with a scar and a Scleral lens fit showing touch. 17$]$

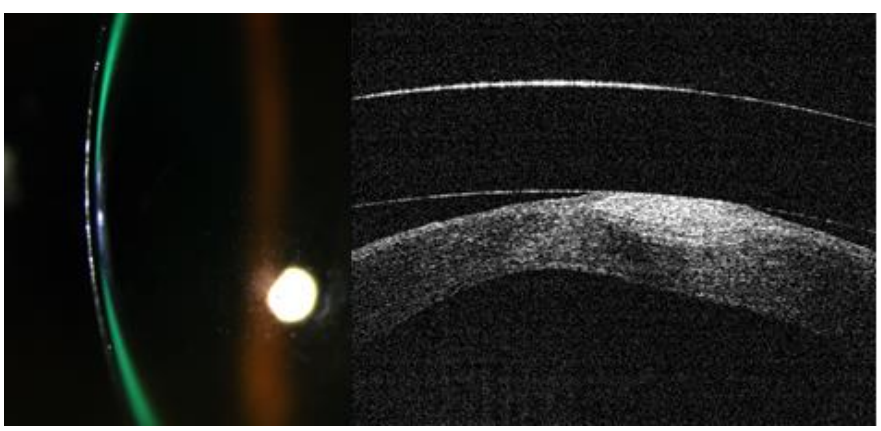

\section{b) Peripheral corneal clearance:[18]}

After evaluating the central corneal clearance the peripheral clearance should be adjusted. This can be done by choosing the Back optic Zone radius of the lens slightly flatter than the flattest Keratometry values which can thus increase the pressure in the Peripheral optical zone and the limbal area.

According need to cite reference on Oxygen transmissibility for scleral lenses, to minimise the hypoxia induced corneal edema, the highest Dk available ie $>150$ with a maximal central thickness of 250 micron and fitted with a clearance that does not exceed 200 micron.

Comparisons of time course of corneal edema using the ASOCT for lower and higher corneal 
Annals of International Medical and Dental Research

E-ISSN: 2395-2822 | P-ISSN: 2395-2814

Vol-8, Issue-2 | March-April 2022

DOI: 10.53339/aimdr.2022.8.2.6

Page no- 25-33 | Section- Research Article (Optometry)

clearance values to establish corneal response curves for varying levels of atmospheric oxygen suggests that an increase in clearance from 230 micron to 430 micron results in a $25 \%$ reduction in oxygen reaching the cornea. (reference)

\section{c) Limbal Clearance:[19]}

Stem cells are present in the limbal area which are crucial for the corneal health in processing new epithelial cells that are distributed over the entire cornea.

A limbal Clearance of 10- 50 micron is ideally needed with maximum being 60 micron that can be accurately measured in an ASOCT. (will show images of conjunctival prolapse, loose edges, tight edges, tight edges at a specific quadrant).

Insufficient limbal clearance can lead to superficial corneal staining, epithelial breakdown, rapid peripheral neovascularisation or scarring. While excessive limbal clearance can result in Corneal bogging, bubbles within the post lens tear layer, corneal hypoxic stress or Conjunctival prolapse. [20]

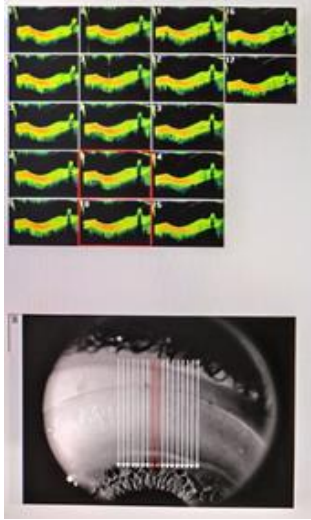

Figure: An ASOCT image showing
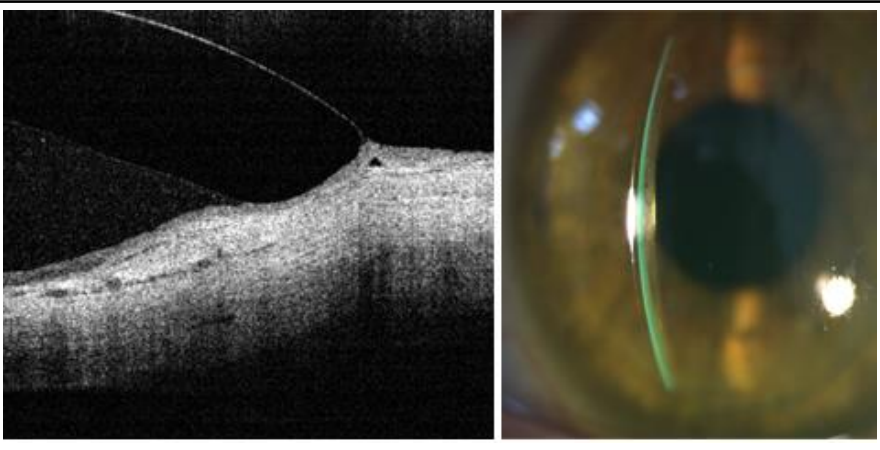

Figure: A Good Limbal Clearance of around 60 micron

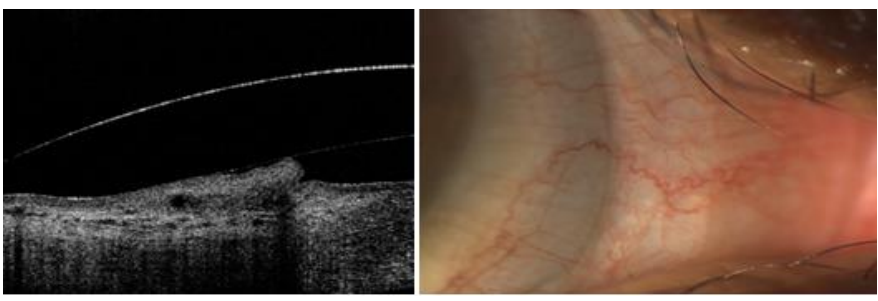

Figure: Low Limbal clearance leading to Mild Mid-Peripheral Compression in ASOCT and Slit Lamp

\section{Landing Zone:[21]}

The landing zone geometry should align as closely as possible with the underlying conjunctival tissue.

On Slit lamp evaluation A ring of bearing on the inner part of the landing zone indicates that the landing zone is too flat, also air bubbles at the periphery can also show the same. While for a steeper lens fit the bearing would be on the outer zone and fluorescein pooling would be visible underneath the landing zone. A steep landing can lift the entire lens off the cornea increasing the total vault of the lens. Also, localised areas of the conjunctiva surrounding the limbus can be "whitened" because compression of the lens on

Conjunctival prolapse 
Annals of International Medical and Dental Research E-ISSN: 2395-2822 | P-ISSN: 2395-2814

Vol-8, Issue-2 | March-April 2022

DOI: 10.53339/aimdr.2022.8.2.6

Page no- 25-33 | Section- Research Article (Optometry)

conjunctiva restricts blood flow called as Circumcorneal conjunctival blanching.

Blanching lead to Compression.[22] Compression doesn't result in conjunctival staining post lens removal but a rebound hyperemia at the area of compression can be seen. A compression whether mild or excessive can be easily seen on an ASOCT. Thus OCT aids in the Haptic zone alignment and thus helping in customisation of Peripheral Lens design.

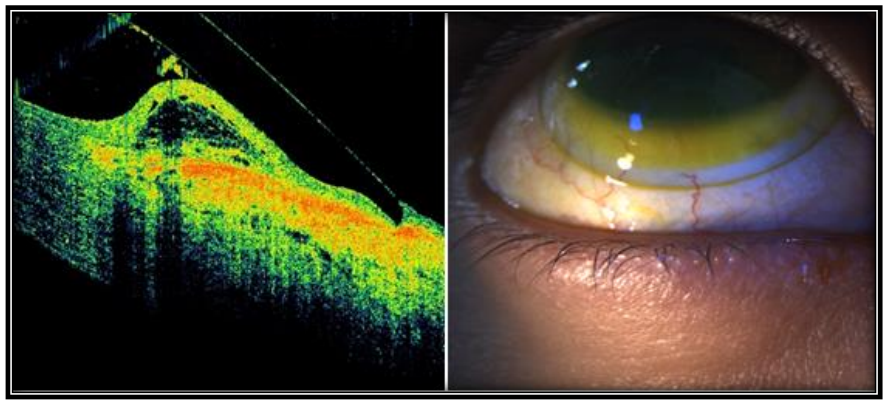

Mid Peripheral Compression

\section{Lens Edge:[23]}

The edge tip or apex should ideally be $50 \%$ sunken into the conjunctiva and $50 \%$ above the surface. Too much edge lift can cause discomfort while low edge lift can cause a focal pinching in the conjunctiva known as edge impingement which leave an impingement ring on lens removal, with corneal stain. Long term impingement may result in Conjunctival hypertrophy.

On Slit lamp evaluation, we have to see how much tear film exchange is occurring by adding fluorescein in the eyes after the lens placement and waiting to see how long it takes for the fluorescein to reach the tear reservoir.
ASOCT can very clearly show the edge lift and the impingement in its cross sectional images . Generally an edge lift of 80 micron or less is sufficient. An edge lift much greater than this can lead to a lot of tear debris accumulation in long term and also cause discomfort to the patient. Mid Day Fogging can occur which is the accumulation of debris or particulate matter within the post lens tear layer, [24] occurring rapidly after the lens insertion. It can reduce visual acuity and the contrast sensitivity. It can be minimised by reducing the lens clearance and altering the haptic and edge alignment. [25]

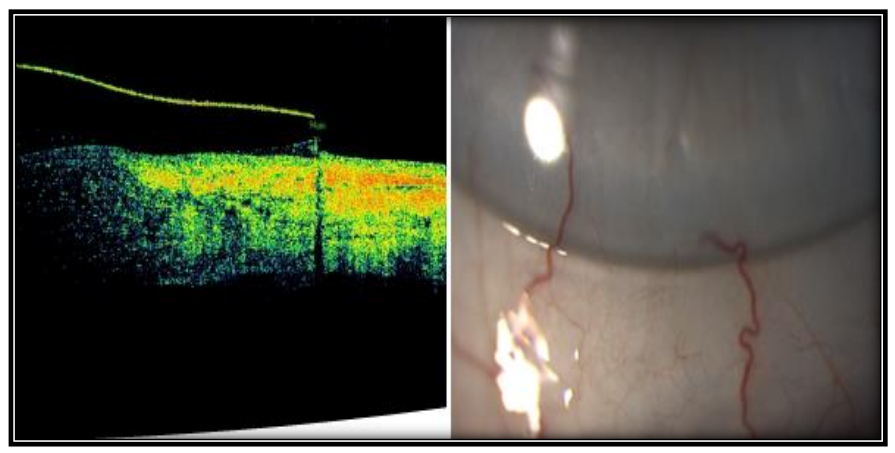

Figure: Loose Fit Showing an edge lift of 94 Microns

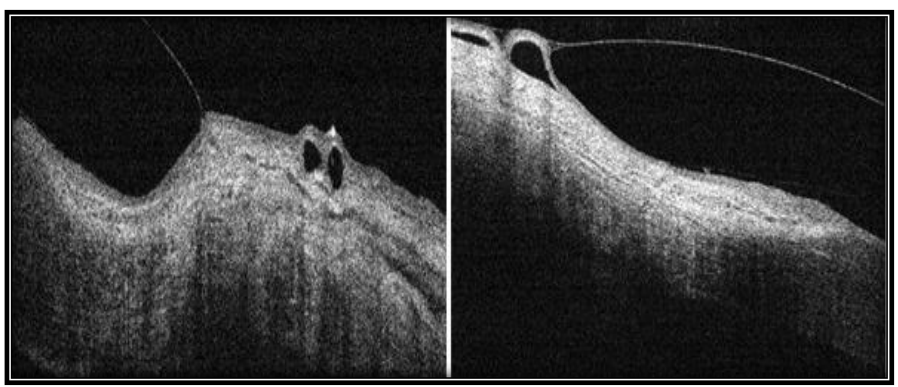

Figure: A Tight Fit showing Edge Impingement in ASOCT 
Annals of International Medical and Dental Research

E-ISSN: 2395-2822 | P-ISSN: 2395-2814

Vol-8, Issue-2 | March-April 2022

DOI: $10.53339 /$ aimdr.2022.8.2.6

Page no- 25-33 | Section- Research Article (Optometry)

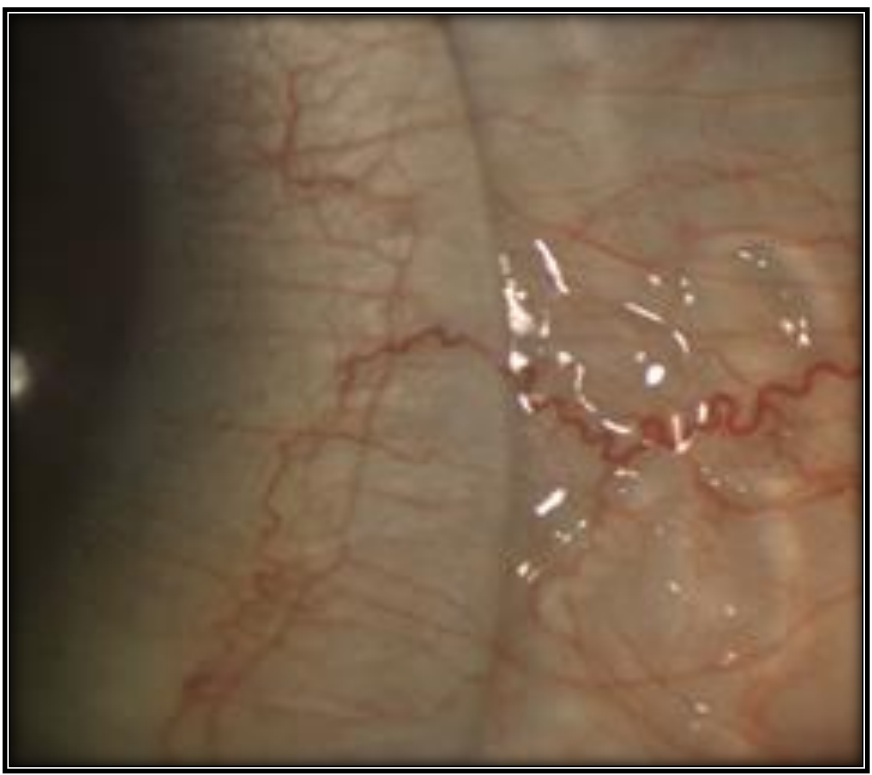

Figure: A Tight Fit showing Edge Impingement in Slit lamp

\section{Scleral lens decentration:[26]}

Scleral lens decenter Infero temporally mostly because of the eye morphology and pressure and sclera height asymmetry. OCT images can be used to quantify lens decentration by calculating the change in separation between the normal to the anterior corneal apex and the normal to the apex of the anterior lens surface for line scans along both horizontal and vertical meridians.

\section{Corneal Hydrops:}

Sometimes after an acute corneal hydrops of a severe Keratoconus patient, regular imaging is valuable for monitoring the healing process of the hydrops while the fitting is done.

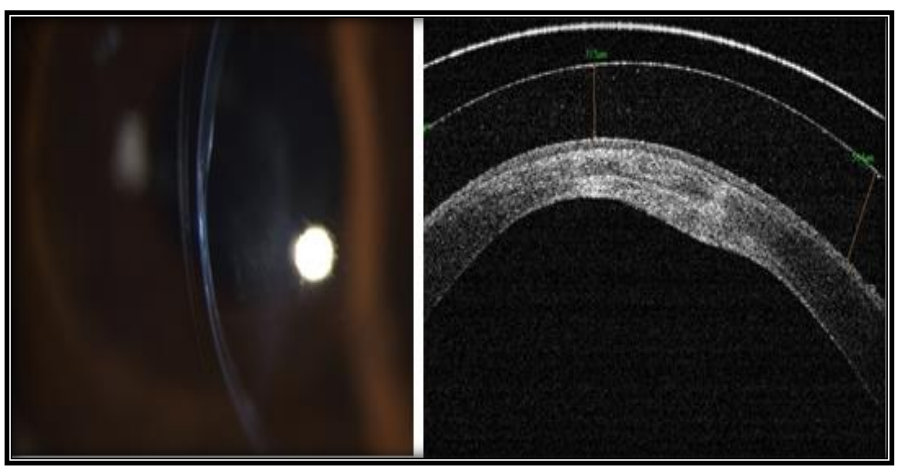

\section{Pachymetry in ASOCT:[27]}

Pachymetry helps to know the Central corneal thickness.

It can be helpful Post fit to rule out corneal edema if any. A baseline corneal thickness can be measured prior lens fit and then on a 6 month follow up a Post lens fit corneal thickness can be evaluated. According to research, 5\% increase in thickness in acceptable amount for daily wear lenses. Thickness greater than $15 \%$ is pathological, as the visual acuity becomes cloudy, infiltrates are present along with epithelial microcysts and neovascularisation is also visible.

\section{CONCLUSIONS}

ASOCT imaging has enhanced the scleral lens practice by refining the initial lens selection, quantitative fit assessment and high resolution imaging of post fit complications. It is thus a powerful tool both for beginners as well as skilled scleral lens practitioners. [28,29]

\section{REFERENCES}

1. Rathi VM, Mandathara PS, Taneja M, Dumpati S, Sangwan VS. Scleral lens for keratoconus:

technology update. Clin Ophthalmol. 2015;9:20132018. doi:10.2147/OPTH.S52483

2. Harthan JS, Shorter E. Therapeutic uses of scleral contact lenses for ocular surface disease: patient 
Annals of International Medical and Dental Research E-ISSN: 2395-2822 | P-ISSN: 2395-2814

Vol-8, Issue-2 | March-April 2022

DOI: 10.53339/aimdr.2022.8.2.6

Page no- 25-33 | Section- Research Article (Optometry)

selection and special considerations. Clin Optom (Auckl). 2018;10:65-74. doi:10.2147/OPTO.S144357

3. Fadel D, Kramer E. Potential contraindications to scleral lens wear. Cont Lens Anterior Eye. 2019;42(1):92-103. doi: 10.1016/j.clae.2018.10.024.

4. Rathi VM, Dumpati S, Mandathara PS, Taneja MM, Sangwan VS. Scleral contact lenses in the management of pellucid marginal degeneration. Cont Lens Anterior Eye. 2016;39(3):217-20. doi: 10.1016/j.clae.2015.11.005.

5. Kompella UB, Kadam RS, Lee VH. Recent advances in ophthalmic drug delivery. Ther Deliv. 2010;1(3):435-456. doi:10.4155/TDE.10.40

6. Schornack MM, Baratz KH. Ocular cicatricial pemphigoid: the role of scleral lenses in disease management. Cornea. 2009;28(10):1170-2. doi: 10.1097/ICO.0b013e318199fa56.

7. Bonini S. Atopic keratoconjunctivitis. Allergy. 2004;59 Suppl 78:71-3. doi: 10.1111/j.13989995.2004.00570.x.

8. Katsoulos K, Rallatos GL, Mavrikakis I. Scleral contact lenses for the management of complicated ptosis. Orbit. 2018;37(3):201-207. doi: 10.1080/01676830.2017.1383475.

9. Şengör T, Aydın Kurna S. Update on Contact Lens Treatment of Keratoconus. Turk J Ophthalmol. 2020;50(4):234-244. doi:10.4274/tjo.galenos.2020.70481

10. Downie LE, Lindsay RG. Contact lens management of keratoconus. Clin Exp Optom. 2015;98(4):299-311. doi: 10.1111/cxo.12300.

11. Ang M, Baskaran M, Werkmeister RM, Chua J, Schmidl D, Aranha Dos Santos V, Garhöfer G, Mehta JS, Schmetterer L. Anterior segment optical coherence tomography. Prog Retin Eye Res. 2018;66:132-156.

10.1016/j.preteyeres.2018.04.002.

12. Shan J, DeBoer C, Xu BY. Anterior Segment Optical Coherence Tomography: Applications for Clinical Care and Scientific Research. Asia Pac J Ophthalmol (Phila). doi:10.22608/APO.201910

13. Macedo-de-Araújo RJ, van der Worp E, GonzálezMéijome JM. Practitioner Learning Curve in Fitting Scleral Lenses in Irregular and Regular Corneas Using a Fitting Trial. Biomed Res Int. 2019;2019:5737124. doi:10.1155/2019/5737124
14. Otchere H, Jones L, Sorbara L. The Impact of Scleral Contact Lens Vault on Visual Acuity and Comfort. Eye Contact Lens. 2018;44 Suppl 2:S54-S59. doi: 10.1097/ICL.0000000000000427.

15. King-Smith PE, Begley CG, Braun RJ. Mechanisms, imaging and structure of tear film breakup. Ocul Surf. 2018;16(1):4-30. doi:10.1016/j.jtos.2017.09.007

16. Marmer RH. Radial keratotomy complications. Ann Ophthalmol. 1987;19(11):409-11.

17. Espandar L, Meyer J. Keratoconus: overview and update on treatment. Middle East Afr J Ophthalmol. 2010;17(1):15-20. doi: 10.4103/09749233.61212.

18. Rathi VM, Mandathara PS, Dumpati S. Contact lens in keratoconus. Indian J Ophthalmol. 2013;61(8):410-415. doi:10.4103/0301-4738.116066

19. Yeung D, Murphy PJ, Sorbara L. Objective and Subjective Evaluation of Clinical Performance of Scleral Lens with Varying Limbal Clearance in Keratoconus. Optom Vis Sci. 2020;97(9):703-710. doi: 10.1097/OPX.0000000000001561.

20. Fisher D, Collins MJ, Vincent SJ. Conjunctival prolapse during open eye scleral lens wear. Cont Lens Anterior Eye. 2021;44(1):115-119. doi: 10.1016/j.clae.2020.09.001.

21. Fuller DG, Wang Y. Safety and Efficacy of Scleral Lenses for Keratoconus. Optom Vis Sci. 2020;97(9):741-748. doi:10.1097/OPX.0000000000001578

22. Segal O, Barkana Y, Hourovitz D, Behrman S, Kamun Y, Avni I, Zadok D. Scleral contact lenses may help where other modalities fail. Cornea. 2003;22(4):308-10. doi: 10.1097/00003226-20030500000006.

23. Schornack MM, Pyle J, Patel SV. Scleral lenses in the management of ocular surface disease. Ophthalmology. 2014;121(7):1398-405. doi: 10.1016/j.ophtha.2014.01.028.

24. Fogt JS. Midday Fogging of Scleral Contact Lenses: Current Perspectives. Clin Optom (Auckl). 2021;13:209-219. doi: 10.2147/OPTO.S284634.

25. Vincent SJ, Alonso-Caneiro D, Collins MJ. Optical coherence tomography and scleral contact lenses: clinical and research applications. Clin Exp Optom. 2019;102(3):224-241. doi: 10.1111/cxo.12814.

26. Kowalski LP, Collins MJ, Vincent SJ. Scleral lens centration: The influence of centre thickness, scleral topography, and apical clearance. Cont Lens 
Annals of International Medical and Dental Research

E-ISSN: 2395-2822 | P-ISSN: 2395-2814

Vol-8, Issue-2 | March-April 2022

DOI: 10.53339/aimdr.2022.8.2.6

Page no- 25-33 | Section- Research Article (Optometry)

Anterior Eye. 2020;43(6):562-567. doi: 10.1016/j.clae.2019.11.013.

27. Argus WA. Ocular hypertension and central corneal thickness. Ophthalmology. 1995;102(12):1810-2. doi: 10.1016/s01616420(95)30790-7.

28. Akkaya Turhan S, Özarslan Özcan D, Toker E. Use of a Mini-Scleral Lens in Patients with Keratoconus. Turk J Ophthalmol. 2020;50(6):339-342. doi:10.4274/tjo.galenos.2020.56804
29. Harthan J, Shorter E, Nau C, Nau A, Schornack MM, Zhuang X, Fogt J. Scleral lens fitting and assessment strategies. Cont Lens Anterior Eye. 2019;42(1):9-14. doi: 10.1016/j.clae.2018.10.020.

Source of Support: Nil, Conflict of Interest: None declared 